\title{
WHAT HINDERS THE DEVELOPMENT OF CHINESE CONTINUING CARE RETIREMENT COMMUNITY SECTOR? A NEWS COVERAGE ANALYSIS
}

\author{
Xin $\mathrm{HU}^{1,2, *}$, Bo XIA ${ }^{2}$, Yi HU ${ }^{3}$, Martin SKITMORE ${ }^{2}$, Laurie BUYS ${ }^{4}$ \\ ${ }^{1}$ School of Design and the Built Environment, Curtin University, Perth, Australia \\ ${ }^{2}$ School of Civil Engineering and Built Environment, Queensland University of Technology, Brisbane, Australia \\ ${ }^{3}$ School of Economics and Management, Tongji University, Shanghai, China \\ ${ }^{4}$ School of Design, Queensland University of Technology, Brisbane, Australia
}

Received 22 August 2017; accepted 16 April 2018

\begin{abstract}
The continuing care retirement community (CCRC) is an emerging institutional living arrangement for the increasing number of older Chinese and has attracted a variety of investors from different sectors in China. However, the development of this sector is still in its infancy and encounters various barriers. This paper aims to explore what hinders the development of the Chinese CCRC industry based on a comprehensive content analysis of news coverage retrieved from 14 major Chinese portal websites. Twenty-one barriers are identified, and they are closely related to the development and operation of CCRCs, government policies and industry management, and potential and current customers. Of all the barriers, the high risks involved in the delivery of CCRCs, lack of policy support, and affordability issue are the most frequently mentioned barriers relating to CCRC development and operation, government policies and industry management, and customers, respectively. These identified barriers call for close collaboration cross various CCRC stakeholders in order to ensure healthy development of the Chinese CCRC industry in the future. This study systemically explores the barriers hindering the development of the burgeoning Chinese CCRC sector, and its findings will benefit CCRC stakeholders and the Chinese CCRC industry in a number of ways.
\end{abstract}

Keywords: continuing care retirement community, barriers, news coverage, content analysis, China.

\section{Introduction}

There is an increasing proportion of older people in China, mainly due to the one-child policy and a general increase in health and longevity. The proportion of people aged $65+$ years rapidly increased from $7.67 \%$ to $9.45 \%$ during $2005-2015$, and is projected to increase to $11.70 \%$ by 2020 (United Nations, 2015). This significant demographic change is placing pressure on the Chinese government and society to house and care for the expanding number of people in the older cohort.

Traditionally, the majority of older Chinese people prefer living in their own home or their children's home, which has resulted in strong intergenerational cohesion with family members (Ren \& Treiman, 2008). Meanwhile, those in need of intensive health care services, accounting for a small proportion of older people, reside in eldercare institutions (e.g., nursing homes) (Chu \& Chi, 2014). In spite of the important roles that these living arrangements have historically played, there are a number of changes evolving within families and in the community that are beginning to impact on these traditional arrangements. For instance, the availability of family support is declining due to a reduction in the household size, lifestyle changes in employment and family expectations. The affordability of residential care is becoming a challenge for many older Chinese people who require care in later life. Together, these issues are contributing to a feeling of dissatisfaction of life after retirement for older people (Lin, 2014).

The continuing care retirement community (CCRC) is an emerging residential living arrangement for older people in China. It is designed as an age homogeneity facility, providing residents with diverse services and amenities to meet their changing needs in one setting (Moen \& Erickson, 2001). The CCRC living can benefit residents in various ways such as their improved health conditions and social interaction levels (Jenkins, Pienta, \& Horgas, 2002). The Chinese government enacted and implemented

*Corresponding author. E-mail: xin.hu@curtin.edu.au 
the policy of "Several Opinions of the State Council in Accelerating the Development of the Senior Service Industry" in 2013 to encourage the participation of social capital in senior service provision (State Council, 2013). This substantially promotes the development of social capital funded CCRCs, as can be seen from the increasing number of investors entering into this market, especially from the real estate industry and the insurance sector.

Compared with the relatively mature CCRC market in developed countries such as the United States and Australia (Simpson \& Cheney, 2007), the development of the CCRC sector in China is in its infancy. Despite so, owing to the increasing number of older adults in China, the volume of the CCRC market is expected to rise significantly in the next decades. Nevertheless, the achievement of this aim requires to overcome a variety of barriers with which the industry is currently confronted. It is also essential for the stakeholders to identify and understand these barriers. First, the domestic industry practitioners are keen to understand these barriers for the purpose of formulating effective property management strategies, which is crucial for them to obtain competitive advantages especially in the initial stages of the industry development. In addition, given that some foreign CCRC developers are seeking appropriate chances of entering into the Chinese CCRC market (e.g., the Australian developers), the understanding of these barriers promotes their understanding of the unique features of the Chinese market and facilitates their decision-making. Moreover, as there is still a lack of related explorations in the Chinese market, this study becomes essential to provide both the researchers and practitioners the evidence of examining these barriers. This will also provide the foundation of the future explorations regarding the development of the Chinese CCRC industry.

Therefore, the aim of this study is to explore what hinders the development of the Chinese CCRC industry. The study will contribute significantly to the strategic property management field. First, the study introduces strategic property management approaches to the Chinese CCRC sector from the perspective of barriers of impacting industry development. The property management strategies are not new to the CCRC sector in some developed countries, but few evidences are available in the Chinese market. In addition, the research findings will not only provide valuable implications to the industry practitioners, but also help the government formulate appropriate strategic property management strategies to ensure the healthy development of this sector.

\section{Living arrangements of older Chinese people}

Living arrangement profoundly affect the well-being of older adults and varies greatly in different contexts (Michael, Berkman, Colditz, \& Kawachi, 2001; Ye \& Chen, 2014). The current living arrangements for older Chinese mainly comprises of ageing at home and ageing in eldercare institutions.

\subsection{Ageing at home}

Ageing at home, usually co-residing with family members, is the most popular living arrangement for older adults in China (Silverstein, Cong, \& Li, 2006). When required, care is provided by the family members and within their local community. For older people, there are diverse reasons for choosing this living arrangement. Connecting with family members and maintaining strong intergenerational cohesiveness are highly valued by older people (Ren \& Treiman, 2015). In addition, the conventional Chinese cultural pattern of filial piety, which obliges family members to provide assistance to their elders, has contributed to the close connections between different generations (Mao \& Chi, 2011). The Chinese government has also enacted laws (e.g., the Elders' Protection Law) to maintain this traditional family support system to care for older people financially, physically and emotionally (Wu, Carter, Goins, \& Cheng, 2005). Moreover, the absence of national public pensions and long-term care programs, especially in rural areas, has made elderly Chinese more dependent on their children as their main care service providers (Silverstein et al., 2006). It is believed that this traditional multigenerational co-residence household pattern has benefited older people in various ways, such as in facilitated material support and reduced loneliness and isolation (Ren \& Treiman, 2015).

As the prevalence of the traditional multigenerational household arrangement gradually diminishes, there are emerging trends of non-traditional households (Silverstein et al., 2006; Ye \& Chen, 2014). For example, the generation-skipping household (older people living with grandchildren and not with their children) and the empty-nest household (older adults living alone or with their spouse) are emerging due to reasons such as the relocation of working-age children by internal migration caused by China's urbanization (Ren \& Treiman, 2015; Xie, Zhang, Peng, \& Jiao, 2010). Additionally, many older Chinese, especially urban residents, are choosing to live independently due to their increased financial independence (Ye \& Chen, 2014).

\subsection{Ageing in eldercare institutions}

Two kinds of social welfare-based eldercare institutions, She-hui-fu-li-yuan (social welfare institutions) and Jinglao-yuan (homes of respect for the elderly), were developed as a method of delivering assistance to low-income older people in need who live in the community. However, with recent economic reforms and the development of a market economy in China, some government-owned institutions are required to become self-financed. As a result, the residents have gradually transitioned from being solely publicly-paid to being self-funded residents who can afford the service and accommodation fees (Chou, 2010; Li, Zhang, \& Liang, 2009). Other types of eldercare institution that are funded mainly by private funding, such as Yang-lao-yuan (institutions for providing care for older adults), CCRCs and residential aged care, have also been 
developed to provide older adults with relative high socioeconomic status, with residents self-funding the rent or purchase price and on-going daily costs.

In China, the decision to move to a residential eldercare is complex, usually involving considerations involving the older person, their family and local community. The decision to move can be influenced by perceived family harmony, filial piety, socio-cultural beliefs and practices involved in raising children and providing eldercare, knowledge and opinion of eldercare institutions and selfassessed economic status (Chou, 2010). Although an increasing number of older people choose to receive longterm care services in an institutional environment (Feng et al., 2011), there are nationwide reports of empty beds (Chou, 2010). One reason may be the stigmatization of institutional care due to its contrast with the traditional value of filial piety (Zhan, Liu, Guan, \& Bai, 2002). After the move, generally, residents evaluate the quality of eldercare institutions highly in terms of facilities and provision of care services, and the majority of residents report improved emotional and physical conditions after relocation (Zhan, Liu, \& Guan, 2006).

\section{Brief review of the Chinese CCRC market}

A CCRC project combines different residential and care options, from independent living to skilled nursing care, to provide residents a continuum of care in one place (Moen \& Erickson, 2001). CCRC projects in China can be either accommodations designed for the older generation in a residential community or independent living retirement communities. The former facilitates introduces older Chinese people to family and community care services (e.g., the Xinfuhui project developed by Vanke), and the latter supports the provision of institutional care services in an age homogeneous community (e.g., the Taikang Community project developed by Taikang Life).

The development of the Chinese CCRC sector is in its infancy, and its development is currently receiving increasing attention from investors, which can be grouped into real estate corporations (e.g., Poly Real Estate and Vanke), senior service institutions (e.g., Qinheyuan Corporation and Starcastle), insurance companies (e.g., Taikang Life, Union Life and China Life) and other investment institutions (e.g., HKING Group) (Deloitte, 2014). It is predicted by a number of independent agencies, such as the Great Wall Securities (2014), Deloitte (2014) and Colliers International (2015), that the development of the Chinese CCRC market will increase gradually in the future. In particular, the potential CCRC market in firsttier cities such as Beijing, Shanghai and Guangzhou is extremely large given the higher proportion of older people and higher disposable household income in these cities (Colliers International, 2015).

Despite the predicted potential of the CCRC market in China, its development is lagging behind when compared with developed countries. For example, in Australia and New Zealand, around 5\% of 65+ older adults reside in CCRCs, and this figure is higher in the United States where approximately $9 \%$ of older people choose this living arrangement (Hu, Xia, Skitmore, Buys, \& Zuo, 2017b; Zuo, Xia, Barker, \& Skitmore, 2014). In China, based on the "9073 Pattern" suggested by some local governments such as Shanghai, only 3\% of older people in 2011-2015 resided in eldercare institutions. A clear understanding the factors that hinder the CCRC development in China will be useful for its future improvement, including policy-making, technological application, sustainability integration (Hu et al., 2017b; Zhong \& Wu, 2015; Chong, Lee, \& Wang, 2017) and project control (Chen, Jin, Xia, Wu, \& Skitmore, 2015).

\section{Research method}

News coverage contains valuable information, and analyzing news coverage provides a feasibility way of exploring the various aspects of a phenomenon through excavating the story behind it and perception of field experts (An \& Gower, 2009). It also allows the explorations of the complex inter-relationships between a phenomenon and its surrounding environment. The method has been adopted in a broad range of contexts, including the property management filed. For instance, by employing newspaper coverage analysis, Munro (2018) examined the housing price inflation issue in the United Kingdom. Mercille (2014) examined the mainstream media coverage to explore the housing bubble issue in Ireland. Landriscina (2012) explored the meanings about homeownership, home-buying, and market behavior through analyzing articles published in The New York Times. The successful explorations of these related studies indicated that news coverage analysis can shed light on the property management issues.

Analyzing reported news coverage is the method adopted in this study to explore the barriers to the development of the Chinese CCRC sector. Several reasons contribute to the use of this method. First, the increasing popularity of CCRC development in China has contributed to an increase in related news reports in mass media. According to the Code of Ethics of the Society of Professional Journalists, news coverage is accurate, fair and thorough (Society of Professional Journalists, 2015). A close examination of related news reports found that they were reported based on either real case studies of CCRC developments or interviews with CCRC stakeholders or professionals (e.g., government officers, academics, customers, senior managers of CCRC developers, and managers of CCRC projects), and therefore the news reports contain valuable, knowledgeable and believable information about current issues emerged in the Chinese CCRC sector. In addition, it is time- and sources- consuming to adopt traditional methods (e.g., interviews and questionnaire survey). Especially, to obtain robust and comprehensive research results, it is necessary to collect rich historical related exploration outcomes or recruit as many industry practitioners as possible. However, as the development of the Chinese CCRC sector is still in its initial stages, there 
are no adequate historical explorations regarding this issue and the Chinese industry professionals who are currently still groping the best way of offering their services in this industry lack experience compared with those from the United States, the United Kingdom and Australia. Instead, analyzing reported news coverage by adopting the content analysis provides more objective and reliable results (based on real and "mute" evidence) and consumes less time and resources. Moreover, given the lack of previous efforts in exploring this issue, analyzing news reports in this primal exploratory research can provide valuable implications for further investigations by using other methods such as interview and questionnaire survey. In fact, analyzing news reports has been used in a number of published studies, such as Atkin, Smith, McFeters, and Ferguson (2008), Qu Tahvanainen, Ahponen, and Pelkonen (2009) and Martins et al. (2013), confirming its usefulness and robustness in understanding certain issues.

Content analysis, an approach often used to analyze news coverage (Calloway, Jorgensen, Saraiya, \& Tsui, 2006; $\mathrm{Qu}$ et al., 2009), was also used in this research to gain insights from the identified news reports. It is a systematic and objective research method for making valid inferences from collected data to describe and quantify specific phenomena (Downe-Wamboldt, 1992). Its suitability to analyze news coverage has been clearly confirmed in the historical studies such as An and Gower (2009). Two crucial steps are involved, comprising the data collection (the identification and collection of news coverage of the development of the Chinese CCRC industry) and data analysis (the analysis of the collected news coverage in both qualitatively and quantitatively) (Figure 1).
The collection of news coverage involves:

- Determining news coverage sources. The Internet provides a convenient means of accessing news coverage. It has the advantages of the easy access to a large volume of news coverage, efficient searching by using keywords and is free of charge. Given that much of the news coverage associated with the Chinese CCRCs market has been released or reprinted in major portal websites, the sources of the news coverage adopted in this research were major Chinese portal websites. Other sources (e.g., newspapers and magazines) were not used as it is too inefficient to collect and search related news coverage in this way and they often involve access charges. The list of "Top Sites in China" released by the Alexa web ranking service provider facilitated the identification of the major Chinese portal websites used in this study (Alexa, 2015). Alexa lists the top sites in each country/territory, and its reliability and usefulness as well accepted (Jowkar \& Didegah, 2010). In this study, 14 major Chinese portal sites listed among the top-50 Chinese sites in Alexa 2015 were identified and employed (Table 1). The remaining 36 sites are specialized websites focusing on the provision of specific services such as internet search, social media, video, forum and shopping. Only a few related news reports were found in these websites, and therefore, they are not used in this study.

- Retrieving news coverage relating to Chinese CCRCs. A search strategy was developed by using Google's searching rule of restricting the research range to

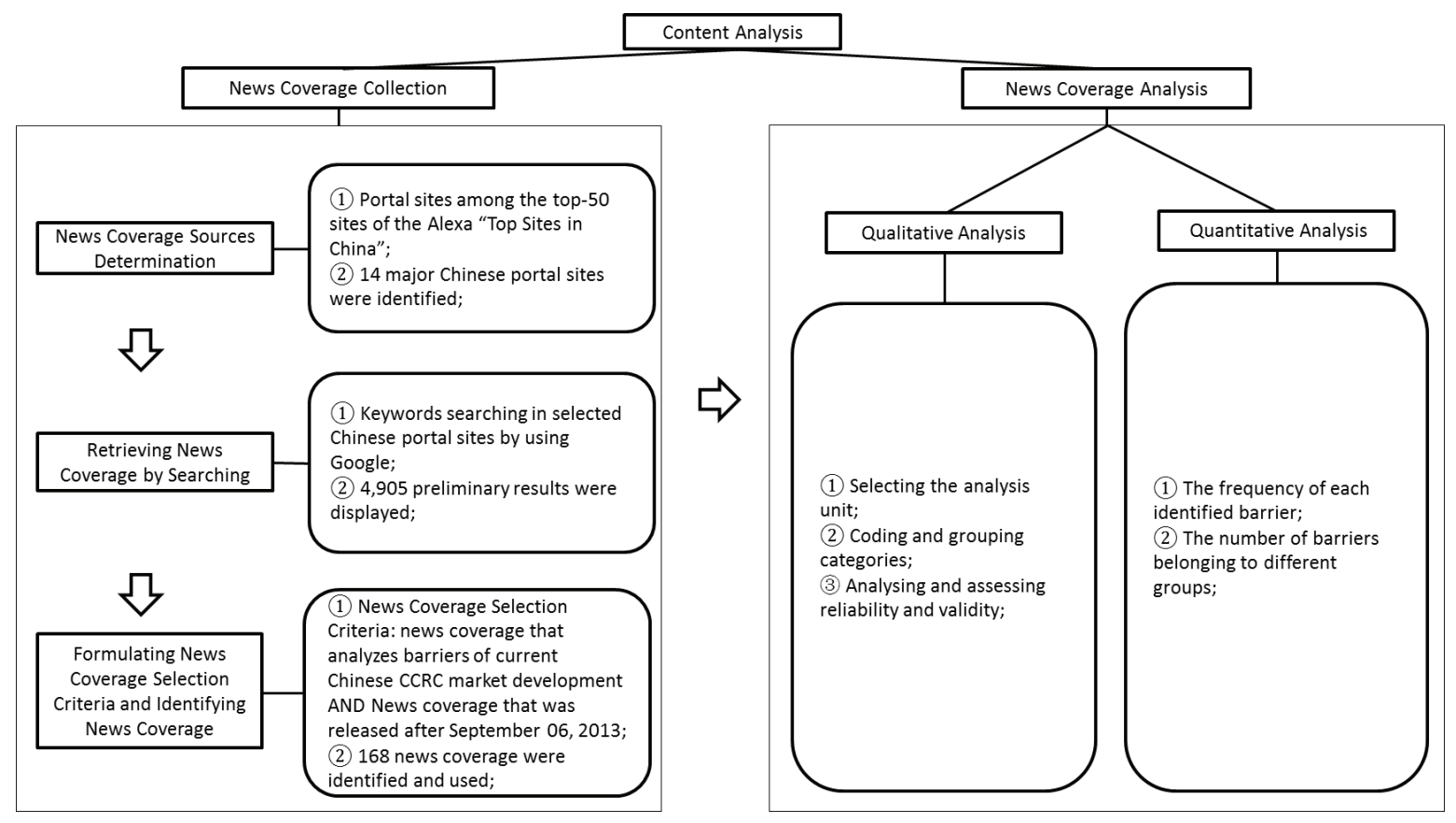

Figure 1. The content analysis process 
Table 1. The 14 major Chinese portal sites for news coverage analysis

\begin{tabular}{|c|l|c|}
\hline Code & \multicolumn{1}{|c|}{ Website } & $\begin{array}{c}\text { Rank in Alexa } \\
\text { list (2015) }\end{array}$ \\
\hline 1 & Qq.com & 3 \\
\hline 2 & Sina.com.cn & 4 \\
\hline 3 & Sohu.com & 8 \\
\hline 4 & $163 . c o m$ & 12 \\
\hline 5 & Cntv.cn & 13 \\
\hline 6 & Gmw.cn & 14 \\
\hline 7 & People.com.cn & 15 \\
\hline 8 & Xinhuanet.com & 16 \\
\hline 9 & Chinadaily.com.cn & 19 \\
\hline 10 & China.com & 23 \\
\hline 11 & Ifeng.com & 32 \\
\hline 12 & China.com.cn & 33 \\
\hline 13 & Caijing.com.cn & 42 \\
\hline 14 & Eastmoney.com & 49 \\
\hline
\end{tabular}

each portal website. Google was used as it is the most influential and powerful search engine in the world. Given that most related news coverage is reported in Chinese, the searching keywords were Chinese based. Different Chinese phrases were employed to represent CCRC in news coverage although these phrases may not always have the exact meaning with CCRC. A close examination of the news coverage before searching identified six Chinese phrases commonly used to represent CCRC, including "Laonian Gongyu (老年公寓)”, “Laonian Shequ (老年社区)”, “Laonian Dichan (老年地产)”, “Yanglao Gongyu (养老公寓)”, “Yanglao Shequ (养老社区)” and “Yanglao Dichan (养老地产)”. To obtain a comprehensive search result, the six Chinese phrases were employed individually to search in each portal site during April-June 2015 and October 2016. For instance, the keyword “老年 公寓” was used to search the “Qq.com” site by adopting “老年公寓” site:qq.com in the Google search bar. The search results were restricted to "Google News". In all, 4,905 results were obtained and retained for further analysis.

- Formulating news coverage selection criteria and identifying news coverage. News coverage selection criteria were formulated to determine which news coverage could be used. First, news coverage that analyzed barriers to the development of the current Chinese CCRC sector were selected by assessing their titles and contents. In addition, given that the policy of the "Several Opinions of the State Council in Accelerating the Development of Senior Service Industry" that was enacted on 6 September 2013 has profoundly affected the development of the Chinese CCRC market, only news coverage released after the enactment date of this policy was selected. Finally, 168 news reports were identified for analysis.
Of these 168 new reports, most were released in 2014 (68) and 2015 (47). The numbers of new coverage in 2016 (before October) and 2013 (after September) are 27 and 26 respectively.

Both qualitative and quantitative analyses were used. The qualitative analysis involved identifying and coding barriers and categorizing barriers into different groups, which followed the process of selecting the analysis unit, coding and grouping categories, and analyzing and assessing reliability and validity. First, the analysis unit is the basis for reporting analyses and the most appropriate analysis unit is whole interviews or observational protocols (Graneheim \& Lundman, 2004). In the study, the unit of analysis is each news coverage which is large enough to consider as a whole and analyze as a context for the meaning unit. Second, coding and grouping categories can be conducted based on either pre-determined systems/frameworks or analysis of collected data (Downe-Wamboldt, 1992). Owing to the lack of related systems and frameworks, the study relied on the analysis of collected news coverage data. The keywords/phrases adopted to depict the barriers were identified by carefully reviewing each news coverage. Some news coverage used the paragraphbased descriptions to illustrate barriers, and therefore a terse phase will be summarized to describe the barriers of them. The barriers with the same meanings were grouped into a same group. These identified barriers were further classified into different categories. Third, the identified barriers and their categories were retained by using a Microsoft Excel document to establish a database. The review and analysis process of each news coverage provided the opportunity of double-checking the reliability and validity of the data analysis process. Inappropriate barrier names and classification can thus be revised in the process. The quantitative analysis was additionally employed to count the number of barriers and calculate their frequency of occurrence based on the qualitative analysis results.

\section{Results}

Table 2 shows the 21 barriers identified and their frequencies based on the content analysis. The top barrier with the highest frequency is High risks due to the large investment, long development and operation cycles, and low investment return of a CCRC project (67.27\%). This is followed by the Immature profit patterns and Affordability issue, with all their frequencies being over $50 \%$. The barriers of Limited government supervision of the CCRC project development, Health system care issues in China, and Lack of a unified CCRC administrative agency have frequencies less than $10 \%$.

These identified 21 barriers were classed into different, comprising the development and operation, government policies and industry management, and potential and current customers. As shown in Table 2, 12 (57.14\%) of the barriers are associated with the development and operation of CCRCs, with another 6 and 3 barriers being closely related to government policies and industry management, and potential and current customers, respectively. 
Table 2. Barriers to the development of the Chinese CCRC industry

\begin{tabular}{|c|c|c|c|}
\hline Category & Code & Barrier & Frequency $(\%)$ \\
\hline \multirow[t]{12}{*}{$\begin{array}{l}\text { Development and } \\
\text { management }\end{array}$} & 1 & $\begin{array}{l}\text { High risks due to the large investment, long development and operation cycles, and } \\
\text { low investment return of a CCRC project }\end{array}$ & 67.27 \\
\hline & 2 & Immature profit patterns & 55.36 \\
\hline & 3 & Speculation behaviors of CCRC developers in land acquisition and use & 40.48 \\
\hline & 4 & Limited and un-qualified on-site services and facilities provision & 34.52 \\
\hline & 5 & $\begin{array}{l}\text { Limited experience of village developers on CCRC project development and } \\
\text { operation }\end{array}$ & 33.33 \\
\hline & 6 & Lack of qualified management, operation and health care provision professionals & 20.24 \\
\hline & 7 & Limited understandings of CCRC developers of older people's requirements & 18.45 \\
\hline & 8 & The difficulties of obtaining land & 16.67 \\
\hline & 9 & Difficulties in financing & 16.67 \\
\hline & 10 & Inappropriate CCRC location & 12.50 \\
\hline & 11 & Lack of CCRC admission criteria & 11.90 \\
\hline & 12 & Lack of service providers & 10.71 \\
\hline \multirow{6}{*}{$\begin{array}{l}\text { Government } \\
\text { policies and } \\
\text { industry } \\
\text { management }\end{array}$} & 13 & Lack of policy support & 43.45 \\
\hline & 14 & Existing policy constraints & 17.26 \\
\hline & 15 & Lack of CCRC industry standards & 14.29 \\
\hline & 16 & Limited government supervision of the CCRC project development & 8.93 \\
\hline & 17 & Health system care issues in China & 7.14 \\
\hline & 18 & Lack of a unified CCRC administrative agency & 3.57 \\
\hline \multirow{3}{*}{$\begin{array}{l}\text { Potential and } \\
\text { current customers }\end{array}$} & 19 & Affordability issue & 51.79 \\
\hline & 20 & Traditional cultural patterns of elderly Chinese & 23.21 \\
\hline & 21 & Conservative attitudes toward consumption of elderly Chinese & 10.71 \\
\hline
\end{tabular}

\section{Discussions}

Stakeholder theory indicates that the groups and individuals that affect, or are affected by the implementation of the business activities should be given a high priority of management (Laplume, Sonpar, \& Litz, 2008). A close examination of these identified barriers found that they are related to different stakeholders, such as CCRC developers, government departments and residents, most of which are key practitioners that profoundly impact the development of the Chinese CCRC sector. It was confirmed with the prior study of Hu et al. (2015a), where it stated that all these stakeholders are crucial in the development and operation of CCRCs and their expectations and concerns should be well addressed. CCRC developers are both the investors and decision-makers of CCRC developments. Their understanding of the CCRC environment and prospective residents' needs profoundly affect the quality of CCRC projects profoundly (Carstens, 1993). Government departments are the administrative agencies of the CCRC market, and they influence the development of the CCRC sector mainly through industry standards and policies. Residents are the end user of a CCRC product. To ensure their life quality and satisfaction, the CCRC living environment should be in balance with their needs and competencies (Hu, Xia, Skitmore, \& Buys, 2015b; Moen \& Erickson, 2001).

The most mentioned barrier relating to the development and operation of CCRCs is the high risks involved in the delivery of a CCRC project. Project risk management theory indicates that risk assessment is the first step of risk management (Raz \& Michael, 2001). A further examination of these high risks found that they are mainly resulted from the large upfront investment, long development and operation cycles and low investment return of a CCRC project. The high investment is due to the development of CCRCs being not only concerned with the construction of accommodation for residents, but also the provision of an age-friendly environment where senior-oriented design (e.g., the barrier-free access, handrails), on-site services and facilities provision and accessibility, professionals management (e.g., managers and caregivers). Project daily operation and management (e.g., organizing social activities and events) should also be well considered to satisfy the residents' needs, such as independent living, social interaction and safety (Campbell, 2015; Hu, Xia, Skitmore, \& Buys, 2018). In addition, a CCRC project has relatively long development and operation cycles, as the developers should provide continued care services to residents. Experience from Australia indicates that some developers may operate their projects for more than 50 years. However, the investment return of a CCRC project is only around $30-50 \%$ of a residential project, with the estimated annual investment rate being around $8-10 \%$ for long-term renting CCRCs in China (Great Wall Securities, 2014; Guotai Junan Securities, 2013). Thus, compared with residential projects that have a gross profit ratio of $20-30 \%$, the gross profit ratio 
of a Chinese CCRC project is only around 10-20\% (Colliers International, 2015). Based on the risks identified and analyzed, risk control by using suitable risk management strategies is of great importance to project success (Raz \& Michael, 2001). Thus, appropriate risk management strategies are required to mitigate risks. This can pose a great challenge to the Chinese stakeholders given their limited experience of the CCRC developments. One feasible way is to learn lessons from other developed countries such as Australia, the United Kingdom, and the United States, where the CCRC industry is already maturely developed.

"Lack of policy support" is the most frequently occurring barrier associated with government policies and industry management. A further examination found that the current policies in the market were enacted either based on the senior service industry or eldercare institution sector, and few policies have been enacted to guide CCRC industry development directly in terms of special land acquisition, tax incentives, project subsidies, investment and preferential financing (Colliers International, 2015; Deloitte, 2014; Research Center of Wis Capital Group, 2010). In addition, some certain policies even constrain the development of CCRC projects. For instance, insurance companies can only hold and rent their CCRCs, owing to the regulation of the China Insurance Regulatory Commission that "the property right of senior real estate projects invested by insurance funds cannot be sold separately, and insurance companies cannot obtain sales revenue through selling the property right of senior real estate projects". Although the renting pattern of CCRCs offers a feasible means of obtaining profits in the long term, it negatively affects the developers' investment returns in the short term.

"Affordability issue" is the most mentioned barrier associated with customers. According to consumer behavior theory, price is a crucial factor impacting consumer behavior. Generally, a high price negatively impacts customers' purchase even if some perceived that a high price means a higher quality and value (Lichtenstein, Ridgway, \& Netemeyer, 1993). Consequently, the un-affordability of the CCRC living significantly hinders the relocation of potential residents from their living environment significantly. Experience from other countries also confirms this conclusion, where the CCRC living cost (e.g., the entry contribution and on-going costs) is an important factor negatively influencing potential residents' CCRC relocation decisions, and older people prefer an affordable residential environment owing to their declining financial situation after retirement (X. Hu, Xia, Skitmore, Buys, \& Y. Hu, 2017a; Krout, Moen, Holmes, Oggins, \& Bowen, 2002). The reasons that affordability is an important issue in China are diverse. For instance, in the one of the richest urban areas of New District, Pudong, Shanghai, the average annual disposable income of a senior citizen family is CNY 38,151 (Pudong Government, 2013), while the living cost of most CCRCs is much higher. Take the Starcastle Zhonghuan project for example, the ongoing monthly cost ranges from CNY 5000 to 30,000 based on unit size (Deloitte, 2014). These high costs prevents a significant proportion of middle class older adults and low-income population from moving to a CCRC (Deloitte, 2014). This is also a similar problem in industrialized countries where CCRC living is more likely to attract relatively affluent retired people (Evans, 2009).

In addition to the "Affordability issue", another customer related barrier is 'attitude of mind' which is closely associated with culture-related factors. According to consumer behavior theory, culture-related factors (e.g., language, religious, social and technological systems) can impact consumer behavior profoundly through impacting their cognitive constructs such as value and perceptions (McCort \& Malhotra, 1993). In the Chinese CCRC sector, it is hard for older people to accept the new institutional living arrangement of CCRCs because of traditional cultural patterns, especially that of filial piety. Filial piety is a special family-oriented value that connects family members of different generations together and requires children to have appropriate attitudes and behaviors to ensure the well-being of older family members (Mao \& Chi, 2011). Older Chinese prefer an inter-generational family life by ageing at home, and institutional living, such as in CCRCs, is often strongly viewed as a negative choice and last resort (Silverstein et al., 2006; Zhan et al., 2002). Conventional attitudes toward consumption, especially thrift and altruism (e.g., leaving money to their children) and no-debt consumption, also negatively influences potential residents' relocation decisions (Mao, Sun, \& Hong, 2013; Research Center of Wis Capital Group, 2010). This contrasts with the developers in Western countries as their senior citizens, especially the baby boomer generation, are characterized as short-term thinkers who are more interested in cash flow and consumption instead of saving (Quine \& Carter, 2006).

\section{Conclusions}

CCRC living is an emerging institutional living arrangement for older people in China. The Chinese CCRC industry is experiencing rapid growth due to the population ageing, policy stimulus and problems with conventional living arrangements. This market has attracted investors from different sectors, such as real estate developers, insurance companies and senior service institutions. Nevertheless, its current development is at an early stage and encounters diverse barriers. Understanding these barriers is the foundation for formulating corresponding strategies for their amelioration by CCRC developers and the government.

Based on the comprehensive content analysis of 168 news reports identified from mainstream Chinese websites, 21 barriers that hinder the current development of the Chinese CCRC sector were identified. These barriers are related to development and operation, government policies and industry management, and potential and current customers. According to frequency of barriers reported in the new coverage analysis, the most significant barriers relating to these three groups are the high risks 
involved in the CCRC delivery, lack of policy support, and affordability issue, respectively.

The research findings of this study will benefit CCRC stakeholders and the Chinese CCRC sector by providing an in-depth understanding of main barriers that hinder the current development of the Chinese CCRC industry, which is a crucial component of their strategic property management. Particularly, this will facilitate the strategic property management decision-making process of potential developers such as whether or not to enter into the Chinese CCRC market. In addition, the research findings will help CCRC developers and government departments obtain corresponding property management strategies to address these identified barriers. Future research, such as case studies, interviews and questionnaire survey, is needed to examine individual barrier more closely and develop practical means for their amelioration and elimination.

The limitation of this study is that the data collection is based on the 14 major Chinese portal websites, which ignores the news coverage in other media sources. In addition, some of the collected data may be not validated as they were reported in the news reports in an anonymous way. Moreover, the study did not distinguish and compare the barriers perceived by different stakeholders as the barriers in the majority of the news coverage was usually reported in a combined and blended way. Future research is needed to clarify.

\section{Acknowledgements}

This work was supported by the Australian Research Council (grant number DP170101208). The authors are grateful to the Australian Research Council for funding the research.

\section{References}

Alexa. (2015). Top sites in China. Retrieved from http://www. alexa.com/topsites/countries;0/CN

An, S. K., \& Gower, K. K. (2009). How do the news media frame crises? A content analysis of crisis news coverage. Public Relations Review, 35(2), 107-112.

https://doi.org/10.1016/j.pubrev.2009.01.010

Atkin, C. K., Smith, S. W., McFeters, C., \& Ferguson, V. (2008). A comprehensive analysis of breast cancer news coverage in leading media outlets focusing on environmental risks and prevention. Journal of Health Communication, 13(1), 3-19. https://doi.org/10.1080/10810730701806912

Calloway, C., Jorgensen, C. M., Saraiya, M., \& Tsui, J. (2006). A content analysis of news coverage of the HPV vaccine by US newspapers, January 2002 - June 2005. Journal of Women's Health, 15(7), 803-809. https://doi.org/10.1089/jwh.2006.15.803

Campbell, N. (2015). Designing for social needs to support aging in place within continuing care retirement communities. Journal of Housing and the Built Environment, 30(4), 645-665. https://doi.org/10.1007/s10901-015-9437-6

Carstens, D. Y. (1993). Site planning and design for the elderly: issues, guidelines, and alternatives. John Wiley \& Sons.

Chen, Q., Jin, Z., Xia, B., Wu, P., \& Skitmore, M. (2015). Time and cost performance of design-build projects. Journal of Construction Engineering and Management, 142(2), 04015074. https://doi.org/10.1061/(ASCE)CO.1943-7862.0001056
Chong, H. Y., Lee, C. Y., \& Wang, X. (2017). A mixed review of the adoption of Building Information Modelling (BIM) for sustainability. Journal of Cleaner Production, 142(4), 41144126. https://doi.org/10.1016/j.jclepro.2016.09.222

Chou, R. J. A. (2010). Willingness to live in eldercare institutions among older adults in urban and rural China: a nationwide study. Ageing and Society, 30(4), 583-608.

https://doi.org/10.1017/S0144686X09990596

Chu, L. W., \& Chi, I. (2008). Nursing homes in China. Journal of the American Medical Directors Association, 9(4), 237-243. https://doi.org/10.1016/j.jamda.2008.01.008

Colliers International. (2015). Twilight China: opportunites for the development of the senior housing market. Retrieved from http://www.colliers.com/-/media/808967CD8BA142C390197 549CD7B68C4.ashx?la=zh-CN

Deloitte. (2014). The aged house for elderly Chinese: current and future development. Retrieved from http://www2.deloitte. com/content/dam/Deloitte/cn/Documents/life-scienceshealth-care/deloitte-cn-lshc-seniorhousing-zh-240914.pdf

Downe-Wamboldt, B. (1992). Content analysis: method, applications, and issues. Health Care for Women International, 1(3), 313-321. https://doi.org/10.1080/07399339209516006

Evans, S. (2009). 'That lot up there and us down here': social interaction and a sense of community in a mixed tenure UK retirement village. Ageing and Society, 29(2), 199-216. https://doi.org/10.1017/S0144686X08007678

Feng, Z., Zhan, H. J., Feng, X., Liu, C., Sun, M., \& Mor, V. (2011). An industry in the making: the emergence of institutional elder care in urban China. Journal of the American Geriatrics Society, 59(4), 738-744. https://doi.org/10.1111/j.1532-5415.2011.03330.x

Graneheim, U. H., \& Lundman, B. (2004). Qualitative content analysis in nurisng research: concepts, procedures and measures to achieve trustworthiness. Nurse Education Today, 24(2), 105-112. https://doi.org/10.1016/j.nedt.2003.10.001

Great Wall Securities. (2014). Senior housing: market, pattern and future. Retrieved from http://www.wisburg.com

Guotai Junan Securities. (2013). The huge market of the senior housing and the slight effects of housing-for-pension program. Retrieved from http://www.wisburg.com

Hu, X., Xia, B., Buys, L., Skitmore, M., Kennedy, R., \& Drogemuller, R. (2015a). Stakeholder analysis of a retirement village development in Australia: insights from an interdisciplinary workshop. International Journal of Construction Management, 15(4), 299-309. https://doi.org/10.1080/15623599.2015.1094848

Hu, X., Xia, B., Skitmore, M., \& Buys, L. (2015b). Conceptualizing sustainable retirement villages in Australia. In A. B. Raidén \& E. Aboagye-Nimo (Eds.), Proceedings 31st Annual ARCOM Conference, Lincoln, UK, 7-9 September 2015 (pp. 357-366). Association of Reserachers in Construction Management.

Hu, X., Xia, B., Skitmore, M., \& Buys, L. (2018). Providing a sustainable living environment in not-for-profit retirement villages: a case study in Australia. Facilities, 36(5/6), 272-290. https://doi.org/10.1108/F-02-2017-0013

Hu, X., Xia, B., Skitmore, M., Buys, L., \& Hu, Y. (2017a). What is a sustainable retirement village? Perceptions of Australian developers. Journal of Cleaner Production, 164, 179-186. https://doi.org/10.1016/j.jclepro.2017.06.227

Hu, X., Xia, B., Skitmore, M., Buys, L., \& Zuo, J. (2017b). Retirement villages in Australia: a literature review. Pacific Rim Property Research Journal, 23(1), 101-122. https://doi.org/10.1080/14445921.2017.1298949

Jenkins, K. R., Pienta, A. M., \& Horgas, A. L. (2002). Activity and health-related quality of life in continuing care retirement communities. Research on Aging, 24(1), 124-149. https://doi.org/10.1177/0164027503024001008 
Jowkar, A., \& Didegah, F. (2010). Evaluating Iranian newspapers' web sites using correspondence analysis. Library Hi Tech, 28(1), 119-130. https://doi.org/10.1108/07378831011026733

Krout, J. A., Moen, P., Holmes, H. H., Oggins, J., \& Bowen, N. (2002). Reasons for relocation to a continuing care retirement community. Journal of Applied Gerontology, 21(2), 236-256. https://doi.org/10.1177/07364802021002007

Landriscina, M. (2012). Framing inflation and investment: the New York Times and the cultural context of a local housing market. Qualitative Sociology, 35(3), 271-292. https://doi.org/10.1007/s11133-012-9230-8

Laplume, A. O., Sonpar, K., \& Litz, R. A. (2008). Stakeholder theory: reviewing a theory that moves us. Journal of Management, 34(6), 1152-1189. https://doi.org/10.1177/0149206308324322

Li, L. W., Zhang, J., \& Liang, J. (2009). Health among the oldestold in China: which living arrangements make a difference? Social Science \& Medicine, 68(2), 220-227. https://doi.org/10.1016/j.socscimed.2008.10.013

Lichtenstein, D. R., Ridgway, N. M., \& Netemeyer, R. G. (1993). Price perceptions and consumer shopping behavior: a field study. Journal of Marketing Research, 30(2), 234-245. https://doi.org/10.2307/3172830

Lin, W. (2014). Challenges of long-term care provisions for the elderly in urban China. China: an International Journal, 12(2), 144-160.

Mao, W., \& Chi, I. (2011). Filial piety of children as perceived by aging parents in China. International Journal of Social Welfare, 20(s1), S99-S108. https://doi.org/10.1111/j.1468-2397.2011.00826.x

Mao, Z., Sun, W., \& Hong, T. (2013). Comparative analysis on the relationship between population age structure and household consumption in China. Population Research, 37(3), 82-92.

Martins, N., Weaver, A. J., Yeshua-Katz, D., Lewis, N. H., Tyree, N. E., \& Jensen, J. D. (2013). A content analysis of print news coverage of media violence and aggression research. Journal of Communication, 63(6), 1070-1087.

https://doi.org/10.1111/jcom.12052

McCort, D. J., \& Malhotra, N. K. (1993). Culture and consumer behavior: toward an understanding of cross-cultural consumer behavior in international marketing. Journal of International Consumer Marketing, 6(2), 91-127.

https://doi.org/10.1300/J046v06n02_07

Mercille, J. (2014). The role of the media in sustaining Ireland's housing bubble. New Political Economy, 19(2), 282-301. https://doi.org/10.1080/13563467.2013.779652

Michael, Y. L., Berkman, L. F., Colditz, G. A., \& Kawachi, I. (2001). Living arrangements, social integration, and change in functional health status. American Journal of Epidemiology, 153(2), 123-131. https://doi.org/10.1080/13563467.2013.779652

Moen, P., \& Erickson, M. A. (2001). Chapter 3 Decision-making and satisfaction with a continuing care retirement community. Journal of Housing for the Elderly, 14(1-2), 53-69. https://doi.org/10.1300/J081v14n01_03

Munro, M. (2018). House price inflation in the news: a critical discourse analysis of newspaper coverage in the UK. Housing Studies, 3(7), 1085-1105.

https://doi.org/10.1080/02673037.2017.1421911

Pudong Government. (2013). The investigation report about the living conditions of senior citizen families in Qudong Xinqu. Retrieved from http://www.pudong.gov.cn/shpd/InfoOpen/ Detail.aspx? $\mathrm{Id}=460407$

Qu, M., Tahvanainen, L., Ahponen, P., \& Pelkonen, P. (2009). Bio-energy in China: content analysis of news articles on Chinese professional internet platforms. Energy Policy, 37(6), 2300-2309. https://doi.org/10.1016/j.enpol.2009.02.024
Quine, S., \& Carter, S. (2006). Australian baby boomers' expectations and plans for their old age. Australasian Journal on Ageing, 25(1), 3-8. https://doi.org/10.1111/j.1741-6612.2006.00147.x

Raz, T., \& Michael, E. (2001). Use and benefits of tools for project risk management. International Journal of Project Management, 19(1), 9-17. https://doi.org/10.1016/S0263-7863(99)00036-8

Ren, Q., \& Treiman, D. J. (2015). Living arrangements of the elderly in China and consequences for their emotional wellbeing. Chinese Sociological Review, 47(3), 255-286. https://doi.org/10.1080/21620555.2015.1032162

Research Center of Wis Capital Group. (2010). Basic research about the retirement housing industry. Retrieved from http:// www.wis.org.cn

Silverstein, M., Cong, Z., \& Li, S. (2006). Intergenerational transfers and living arrangements of older people in rural China: consequences for psychological well-being. The Journals of Gerontology Series B: Psychological Sciences and Social Sciences, 61(5), S256-S266. https://doi.org/10.1093/geronb/61.5.S256

Simpson, M., \& Cheney, G. (2007). Marketization, participation, and communication within New Zealand retirement villages: a critical-rhetorical and discursive analysis. Discourse and Communication, 1(2), 191-222.

https://doi.org/10.1177/1750481307076006

Society of Professional Journalists. (2015). Code of ethics. Retrieved from http://www.spj.org/pdf/spj-code-of-ethics.pdf

State Council. (2013). Several opinions of the state council in accelerating the development of senior service industry. Retrieved from http://www.gov.cn/zwgk/2013-09/13/content_2487704.htm

United Nations. (2015). Population ageing and development database 2014. Retrieved from https://esa.un.org/unpd/popdev/ agedevdb/agedevdb2014.aspx

Wu, B., Carter, M. W., Goins R. T., \& Cheng, C. (2005). Emerging services for community-based long-term care in urban China: a systematic analysis of Shanghai's community-based agencies. Journal of Aging \& Social Policy, 17(4), 37-60. https://doi.org/10.1300/J031v17n04_03

Xie, L. Q., Zhang, J. P., Peng, F., \& Jiao, N. N. (2010). Prevalence and related influencing factors of depressive symptoms for empty-nest elderly living in the rural area of YongZhou, China. Archives of Gerontology and Geriatrics, 50(1), 24-29. https://doi.org/10.1016/j.archger.2009.01.003

Ye, M., \& Chen, Y. (2014). The influence of domestic living arrangement and neighborhood identity on mental health among urban Chinese elders. Aging \& Mental Health, 18(1), 40-50. https://doi.org/10.1080/13607863.2013.837142

Zhan, H. J., Liu, G., \& Guan, X. (2006). Willingness and availability: explaining new attitudes toward institutional elder care among Chinese elderly parents and their adult children. Journal of Aging Studies, 20(3), 279-290. https://doi.org/10.1016/j.jaging.2005.09.006

Zhan, H. J., Liu, G., Guan, X., \& Bai, H. G. (2002). Recent developments in institutional elder care in China: changing concepts and attitudes. Journal of Aging \& Social Policy, 18(2), 85-108. https://doi.org/10.1300/J031v18n02_06

Zhong, Y., \& Wu, P. (2015). Economic sustainability, environmental sustainability and constructability indicators related to concrete- and steel-projects. Journal of Cleaner Production, 108, 748-756. https://doi.org/10.1016/j.jclepro.2015.05.095

Zuo, J., Xia, B., Barker, J., \& Skitmore, M. (2014). Green buildings for greying people: a case study of a retirement village in Australia. Facilities, 32(7-8), 365-381.

https://doi.org/10.1108/F-08-2011-0060 